\title{
Allergic bronchopulmonary aspergillosis in cystic fibrosis
}

\section{To the Editor:}

We believe that the recent report from the Epidemiologic Registry of Cystic Fibrosis into the epidemiology of allergic bronchopulmonary aspergillosis (ABPA) in cystic fibrosis (CF) [1], represents a missed opportunity to present what are potentially very valuable data.

In non-CF populations, a diagnosis of ABPA requires the fulfillment of clearly defined clinical, laboratory, and radiographical criteria. In contrast, the authors arbitrarily characterized their patients as having ABPA on the basis of hypersensitivity to Aspergillus fumigatus and a physician's suspicion that the patient had the condition. The lack of precision consequent on the use of clinical suspicion in the authors' modified diagnostic criteria makes interpretation of the data presented problematic. We accept that ABPA can be very difficult to diagnose accurately in $\mathrm{CF}$ because of the underlying disease. A number of small studies have reported that immunological responses to A. fumigatus are common in CF patients, ranging in frequency from $37-77 \%$, whereas ABPA is found infrequently when strict criteria are used [2-4]. It would have been preferable, therefore, if the data on immunological reactions, with and without clinical suspicion of ABPA, had been presented separately. In addition, we have no means of knowing what proportion of patients in the database underwent the complete range of investigations required for a diagnosis of ABPA. Thus, the true prevalence of ABPA might have been underestimated.

A better appreciation of the true prevalence of $A$. fumigatus hypersensitivity and ABPA in CF is needed to understand their role in disease progression. There is evidence that immune responses to A. fumigatus, which develop at an early age in children with CF [5], may contribute to progressive worsening of respiratory function, possibly by proteinase secretion [6]. For example, WoJNAROwSKi et al. [7] found that the lung function measurements of forced expiratory volume in one second and forced mid-expiratory flow (FEV1 and FEF 25-75) were lower in CF patients sensitized to $A$. fumigatus, and that a raised total immunoglobulin $\mathrm{E}$ (IgE) level was associated with a more rapid decline in lung function [7]. These authors suggested that sensitization to $A$. fumigatus per se may contribute to progressive respiratory disease. However, at present it is still unclear whether the deterioration in lung function in $\mathrm{CF}$ is related to the immune response to A. fumigatus or requires the full-blown syndrome of ABPA. We had hoped that the present publication would help to answer this important question.

If an immunological response to Aspergillus colonization is indeed established as an important pathogenic factor in disease progression, this would call for more aggressive and novel therapies. In a preliminary study [8], for example, we have recently reported that $\mathrm{CF}$ patients with positive immunological reactions to $A$. fumigatus had a good response to the leukotriene receptor antagonist montelukast. Can we encourage the authors to provide a more detailed breakdown of their data so that some of these queries can be addressed?

\section{J.A. Kastelik, I. Aziz, A.E. Redington, A.H. Morice}

Academic Dept of Medicine, Respiratory Medicine, University of Hull, Castle Hill Hospital, Castle Road, Cottingham, HU16 5JQ, UK.

\section{References}

1. Mastella G, Rainisio M, Harms HK, et al. Allergic bronchopulmonary aspergillosis in cystic fibrosis. A European epidemiological study. Eur Respir J 2000; 16: $464-471$.

2. Zeaske $\mathrm{R}$, Bruns $\mathrm{WT}$, Fink $\mathrm{JN}$, et al. Immune responses to Aspergillus in cystic fibrosis. J Allergy Clin Immunol 1988; 82: 73 - 77.

3. Becker JW, Burke W, McDonald G, Greenberger PA, Henderson WR, Aitken ML. Prevalence of allergic bronchopulmonary aspergillosis and atopy in adult patients with cystic fibrosis. Chest 1996; 109: 1536 1540.

4. Nelson LA, Callerame ML, Schwartz RH. Aspergillosis and atopy in cystic fibrosis. Am Rev Respir Dis 1979; 120: 863-873.

5. el-Dahr JM, Fink R, Selden R, Arruda LK, PlattsMills TA, Heymann PM. Development of immune responses to Aspergillus at an early age in children with cystic fibrosis. Am J Respir Crit Care Med 1994; 150: $1513-1518$.

6. Robinson BW, Venaille TJ, Mendis AH, McAleer R. Allergens as proteases: an Aspergillus fumigatus proteinase directly induces human epithelial cell detachment. J Allergy Clin Immunol 1990; 86: 726 731.

7. Wojnarowski C, Eichler I, Gartner C, et al. Sensitization to Aspergillus fumigatus and lung function in children with cystic fibrosis. Am J Respir Crit Care Med 1997; 155: $1902-1907$.

8. Morice AH, Kastelik JA, Aziz I. Montelukast sodium in cystic fibrosis. Thorax 2001; (in press). 